\title{
Ocupação Espaço Comum Luiz Estrela: culturas e sociabilidades na cidade de Belo Horizonte MG - Brasil
}

\author{
Sandra Pereira Tosta ${ }^{1}$ \\ Weslei Lopes Silva ${ }^{2}$
}

\section{Introdução:}

Tendo como título "Culturas Urbanas: Georreferenciamento e Análise Cultural de Grupos Juvenis em sua relação com a Escola, as tecnologias e com a cidade de Belo Horizonte/MG-Brasil", a pesquisa da qual este texto parte se tratou de uma investigação de fôlego, com duração de cerca de quatro anos, a partir da parceria de grupos de pesquisa ligados aos Programas de Pós-Graduação em Tratamento Espacial e o Programa de Pósgraduação em Educação da PUC-Minas, bem como da Escola de Belas Artes da UFMG e cuja coordenação ficou a cargo do EDUC (Grupo de Estudos e Pesquisas em Educação e Culturas da PUC- Minas). Participaram da investigação pesquisadores, mestres, doutorandos e doutores, além de bolsistas de iniciação científica ${ }^{3}$.

A partir da verificação de diversos grupos culturais existentes na cidade de Belo Horizonte/MG, detidamente sua região do hipercentro ${ }^{4}$, a referida pesquisa teve como objetivo primordial o Gerorreferenciamento ${ }^{5}$ e a realização de etnografias de alguns desses grupos. O propósito foi analisar e compreender os perfis desses grupos, seus objetivos, propostas e relações que estabelecem com as escolas e seus projetos de vida. E, ainda, compreender as relações desses grupos com as tecnologias de comunicação,

\footnotetext{
${ }^{1}$ Pontifícia Universidade Católica de Minas Gerais, Brasil

${ }^{2}$ Pontifícia Universidade Católica de Minas Gerais/ Universidade de Itaúna, Brasil

${ }^{3}$ Agradecemos a todos os pesquisadores e bolsistas envolvidos na pesquisa. Haja vista ser um grupo grande, para conhecê-los, recomendamos conferir Tosta et.al. (2016).

${ }^{4}$ Mais adiante no texto, trazemos um mapa que demonstra os limites dessa região da cidade.

${ }^{5} \mathrm{O}$ geoprocessamento é uma técnica para confrontação e análise de informações geoespaciais, que permite associar imagens aéreas e/ou orbitais (Sensoriamento Remoto) com os SIG's, e equipamentos de localização geográfica, como o GPS (Global Positioning System). Estas técnicas relacionam um conjunto de procedimentos que permite associar pontos da superfície terrestre a pontos correspondentes no plano de projeção, no caso, a UTM (Universal Transversa de Mercator), favorecendo assim, a diminuição de erros ou discrepância de posicionamento dos elementos geográficos na confecção dos referidos mapas.

${ }^{5}$ Avenida que contorna a região central de Belo Horizonte e cujo desenho segue o traçado planejado anteriormente à construção da cidade. Originalmente, o projeto previa a urbanização apenas da área limitada pela avenida, mas com o desenvolvimento intenso no século XX a cidade ultrapassou os limites muito antes do esperado.
} 
com a cidade e com as escolas em suas expressões culturais e modos de organização. Seus resultados possibilitaram a produção um Atlas $\mathrm{Cultural}^{6}$ dos grupos de culturas na cidade de belo horizonte e de um documentário etnográfico ${ }^{7}$ sobre a atuação e intervenção desses mesmos grupos na cidade e as possíveis relações com a educação e a escola.

Em consonância a estes objetivos, a construção teórica e metodológica adotada foi de natureza quantitativa com a técnica do georreferenciamento e qualitativa, com a realização de etnografias nos grupos. A etnografia é por nós entendida como um modo específico de produzir conhecimento na matriz disciplinar da antropologia, cujo significado é apreender as relações, os valores, os ideários, as representações e os imaginários que integram as culturas entre os grupos juvenis, juntamente com o georreferenciamento espacial, pesquisa documental, entrevistas e coleta de depoimentos, bem como pesquisa em redes sociais, registros fotográficos e audiovisuais compuseram a metodologia dessa investigação. E no que se refere à pesquisa de campo, ainda que a proposta inicial da investigação tivesse como objeto os vários grupos de jovens que transitavam/ocupavam os diversos espaços do hipercentro da cidade de Belo Horizonte, a investigação se centrou na ocupação Espaço Comum Luiz Estrela, identificado no transcurso da pesquisa como o lugar onde ocorriam intervenções de vários grupos georreferenciados. Foi junto a esses grupos que foram elaboradas as etnografias, realizadas sempre em dupla ou trio, compostos por um pesquisador e bolsista(s) de iniciação científica, modelagem que nos impôs um desafio, qual seja, a tradição da antropologia é a prática de etnografia solo, de um pesquisador. Nesta nossa busca, a experiência etnográfica foi sempre coletiva e na escrita de cada texto, esse coletivo se ampliava para solidaria e academicamente ouvir, opinar, comentar, criticar e sugerir algo sobre a descrição exposta e interpretada.

Para a análise e interpretação dos dados do campo recorremos aos estudos sobre cidades, culturas, juventudes, territórios e movimentos sociais, além da sistematização de categorias nativas que foram surgindo no discurso dos sujeitos dos grupos observados.

Isto posto, ante a amplitude da referida pesquisa, a proposta deste artigo é trazer neste artigo algumas reflexões acerca do "Espaço Comum Luiz Estrela", como um dos grupos pesquisados e que, de modo potente, traduz a construção permanente e mais que heterogênea de ação, intervenção e expressão de cultura na cidade. Ademais, refletir sobre

\footnotetext{
${ }^{6}$ No prelo.

${ }^{7}$ https://wetransfer.com/downloads/8a9b42fed72e8c4385ed9041fd7ed32120160427184558/721dc
} 
como os ativistas e frequentadores do Espaço Comum Luiz Estrela pensam e vivenciam a cidade e quais são seus ideários políticos e culturais e, detidamente, como percebem e constituam a autogestão o em suas ações comunitárias, visto ser essa uma das ideias centrais que engendram e constituem o referido Espaço.

\section{Juventudes em cena?}

No transcorrer da pesquisa, desde a exploração inicial do campo, seja em ambiência física ou virtual, várias questões impuseram ao grupo de pesquisadores o desafio de uma nova problematização teórica e metodológica: a categoria "juventude", vislumbrada como eixo articulador do projeto e organizada em diversas expressões, tais como movimentos, coletivos, grupos, etc.

Importante considerar que na cena social e política na última década do século $\mathrm{XX}$, e principalmente nos últimos cinco anos, a temática da juventude tem ganhado maior projeção e densidade, abrindo-se a estudos com perspectivas variadas em diferentes países. Nesse cenário, temos disponíveis atualmente no Brasil várias pesquisas sobre essa temática, utilizando-se de instrumentos quantitativos e qualitativos, que visam cobrir quase a totalidade do território nacional, mapeando a diversidade de condições da juventude no país.

No âmbito das grandes investigações, podem-se delimitar, pelo menos, duas perspectivas distintas, porém complementares. De um lado, pesquisas em que o foco são os problemas sociais que atingem a população jovem, dentre as quais destacam-se nessa via estudos sobre violência, criminalidade, drogas, abandono escolar, gravidez na adolescência, dentre outros temas que interferem diretamente nas condições concretas, materiais e simbólicas para se entender a condição juvenil no Brasil contemporâneo. (Zaluar, 1997; Abramovay, 2002).

De outro lado, estudos que buscam pensar o jovem e a juventude em sua positividade, destacando, dentre outros aspectos, a cultura como espaço de sociabilidade e inserção social e política juvenil. Nesse caminho duas vertentes podem ser demarcadas: na primeira delas, as culturas e grupos juvenis são focados como tempo/espaço privilegiado de expressão e construção identitária juvenis, bem como territórios de construção de projetos de vida e futuro; já a segunda abordagem busca pensar os jovens como sujeito social e político, agente na sociedade (Abramo, 1994, 2005; Spósito, 2002, 2007; Carrano, 2000, 2003; Dayrell, 2005, 2007; Tosta, 2005, 2006). 
Segundo Dayrell (2007), a condição juvenil contemporânea no Brasil manifestase nas mais variadas dimensões, sendo as principais: as culturas juvenis - entendidas como “expressões simbólicas da condição juvenil"; a sociabilidade - entendida como "uma forma possível de sociação, mas que apresenta características próprias, sendo a principal a sua emancipação dos conteúdos"; o trabalho; a relação que estabelecem com o lugar em que vivem; o tempo e as distintas formas de viver a transição para a vida adulta.

$\mathrm{Na}$ investigação em foco, a juventude foi vislumbrada como uma categoria chave para compreender e analisar as manifestações de grupos culturais em atividade na cidade de Belo Horizonte. Para tanto, essa categoria foi pensada a partir da segunda perspectiva dos estudos citada anteriormente, isto é, pensar o jovem que atua nos grupos culturais em sua positividade, destacando, a cultura como espaço e expressão de sociabilidades e a inserção social e política juvenil. É preciso destacar, no entanto, que à medida do desenvolvimento da investigação, os dados de campo nos levaram a questionar se a categoria juventude, tal como elaborada, conseguiria abarcar e servir como eixo analítico para o perfil dos participantes dos diversos grupos culturais mapeados e/ou etnografados no escopo da investigação. Muito da dificuldade ocorreu ao considerar a questão etária e geracional na categoria juventude, visto que suas idades variavam muito, extrapolando o recorte etário que comumente costuma caracterizar essa categoria ${ }^{8}$.

Para Margullis e Urrest (1996) é fundamental considerar a cronologia nos estudos sobre jovens e juventude pois, segundo reafirmam, a matéria primordial da juventude é sua cronologia, portanto, pensá-la, implicaria, necessariamente, em manter uma base etária, sem esta base a juventude perderia sua especificidade. Mesmo que em termos legais e de acordo com o Estatuto da Criança e do Adolescente, ser jovem é estar na faixa etária entre 12 e 18 anos, vários estudos na Europa e no Brasil têm optado por trabalhar com uma faixa bastante mais alargada, que chega aos 30 anos ou mais, baseando-se em pesquisas que buscam a percepção dos sujeitos e consideram o contexto em que vivem. Nesta perspectiva o ser adolescente e jovem se apresentam muito mais como um sentimento de pertença e de experiência, de "estado de espírito" do que propriamente corresponde a um dado cronológico.

$\mathrm{Na}$ pesquisa de campo da qual partimos, observou-se que, em grande parte, os grupos georreferenciados eram constituídos, majoritariamente, por sujeitos na referida

\footnotetext{
${ }^{8}$ De acordo com os parâmetros das organizações nacionais e internacionais, considera-se atualmente como jovem, sujeitos com idades entre 18 e 29 anos.
} 
faixa etária. Porém, em alguns outros, foi constatada uma conciliação etária bem diversificada e alongada, podendo-se observar uma composição intergeracional. Em tal caso, e mesmo ante o alerta de Margullis e Urrest (1996), não há como negar que a dimensão simbólica é parte da "condição juvenil" e assim, do mesmo modo como não se deve desconsiderar a cronologia na compreensão da juventude, não se pode deixar de lado sua dimensão simbólica, sob o risco de se chegar a uma não compreensão dos fenômenos juvenis estudados, visto que a juventude deixou de ser atributo de um grupo etário jovem, descolou-se da cronologia e tornou-se "signo"; no dizer de Peralva (1997), um modelo cultural. Como nos lembra Bauman (2005), na atualidade nenhum "pertencimento" ou "identidade" tem a solidez de uma rocha, nem é garantido pela vida toda, sendo "bastante negociáveis e revogáveis”. E a tarefa da construção da identidade é, como diria LéviStrauss, a de um bricoleur, que constrói todo tipo de coisa com os materiais que tem a mão (BAUMAN, 2005, TOSTA, 2005).

Ante essas considerações, é factível dizer que nas sociedades contemporâneas o termo juventude deixou de ser considerado um atributo exclusivo dos sujeitos situados na faixa etária jovem, para se tornar um estilo de vida, um projeto perseguido por diferentes sujeitos, visto que o fator idade não se trata do único elemento que a constitui e talvez não seja, inclusive, o mais importante para sua composição. Deste modo, dado o caráter polissêmico que o termo juventude apresenta, definimos por trabalhar com a categoria juventude a partir de referenciais estendidos, entendendo-a como um processo mais amplo de constituição de sujeitos, cujas especificidades marcam a vida de cada um.

Ante isso, na direção de Magnani (2007), importou para a nossa investigação privilegiar a inserção dos jovens no cenário urbano, etnografando por meio dos espaços que frequentam, as relações que mantêm com seus pares e suas relações de troca, seus conflitos e expectativas. Ademais, e fundamentalmente, apreender uma certa tradução do que é ser jovem a partir da observação atenta das narrativas e ações dos sujeitos nos grupos com os quais convivemos.

\section{Pelas ruas, becos e luzes da cidade:}

Ao que tudo indica, a visão é o sentido privilegiado na contemporaneidade, conforme já previra Simmel (2006) tantos anos antes e cuja constatação leva Le Breton (2011:159) a manifestar que "a socialidade urbana induz uma excrecência do olhar e uma 
suspensão ou um uso residual dos outros sentidos, cujos usos, em última instância, o homem só encontra na privacidade de sua casa". Ainda que possa ser assim, a paisagem urbana enquanto cenário de pesquisa antropológica implica por parte do investigador um exercício sinestésico atento aos estímulos que a compreendem, independentemente do objeto de estudo. Importam, pois, para a compreensão da realidade estudada as ambiências, pessoas, caminhares, gestos, olhares, cheiros, sons, cores, ritmos, objetos, enfim, uma diversidade de micro-eventos e situações que compõem as práticas individuais e coletivas, construídas e modificadas no cotidiano da e na cidade (Eckert; Rocha; 2013). Em outras palavras, mesmo que, por vezes, o olhar do antropólogo assuma um lugar de destaque ante as dinâmicas incessantes que habitam os lugares por ele percorridos para a investigação de qualquer realidade social, principalmente quando materializados em imagens estáticas e/ou em movimento que compõem seus registros de campo, o potencial das possibilidades facultadas pelo encontro por meio da fala, dos olhares, da escuta disponível, do tato, da discussão com as personagens presentes em tais espaços não pode ser desprivilegiado.

Haver pesquisado no Espaço Luiz Estrela fez com que os investigadores envolvidos estivessem em permanente contato com dados visuais, mas também olfativos, acústicos, táteis, sinestésicos, dentre outros, que importa(ra)m densamente para que se pudesse compreender como os diversos atores daquele espaço pensam, interagem entre si, representam e vivem a situação de ocupação do prédio e a constituição de um espaço comum constantemente resinificados por seus usuários.

Considerando, na perspectiva de Silva (2009: 174), que "o conhecimento da cidade é, portanto, um conhecimento produzido pelos percursos. Ela nunca se destaca do observador e se oferece como um quadro no museu, para cuja contemplação adequada ele busca, com seus passos que tateiam no chão, o lugar ideal, o ângulo perfeito", várias sonoridades ajudaram a compor as experiências dos pesquisadores no campo e as "imagens" construídas, (re)interpretadas e transpostas para os textos etnográficos. O passo ruidoso das personagens pelos corredores do Espaço Comum Luiz Estrela, por exemplo, o som da água que escapa da torneira, as vozes exaltadas, o canto que vinha do quintal, o estalo da madeira do telhado que parecia querer cair, as risadas, os ecos da rua, os telefones celulares que insistiam em tocar são alguns exemplos que, traduzidos, buscaram demonstrar que estiveram lá e que "se houvéssemos estado lá, teríamos visto o que viram, sentido o que sentiram e concluído o que concluíram" (Geertz, 2002: 29). 
Desde essa perspectiva, as reflexões advindas da investigação no Espaço Comum Luiz Estrela se orientam na perspectiva da consideração da cidade a partir de seu uso e fruição e cujas formas são fluidas e cambiantes, visto que seus espaços são construídos e modificados pelos atores sociais no cotidiano a partir dos modos como deles se apropriam e fazem uso (Lefebvre, 1978). Ancoramo-nos, portanto, em uma abordagem que possibilita pensar e reconhecer a cidade, na direção do filósofo francês, como um produto social que traz em sua materialidade a diferença entre o espaço concebido e projetado por urbanistas, por exemplo, e sua experimentação e fruição pela população no seu dia-a-dia. A cidade é pensada aqui enquanto "texto e contexto de novos debates sobre relações sociais fundamentais" (Holston, 1996: 252), na qual a vida se faz diversa e cada vez mais complexa, em que pese as várias possibilidades de apropriação e reestruturação de seus espaços pelos sujeitos.

Assim, ao pensarmos a cidade, consideramos-na como espaços de relação, de interação e experiência urbana onde grupos e pessoas de diferentes valores, estilos, orientações e práticas se encontram. Nessas interações, nem sempre pacíficas ou bemvindas, uma complexa teia de papéis sociais norteia e configura comportamentos e atitudes, propiciando uma diversificada rede de relações e contatos. A urbe, então, concentra uma heterogeneidade de atores e dá ensejo a uma mobilidade cada vez maior e intensa, em que pese ainda o papel e uso das tecnologias digitais na atualidade, tornando cada vez mais complexas as relações que acontecem na paisagem urbana cujos limites não mais se restringem a seu aspecto físico, geográfico (Lins Ribeiro, 1996, 1997, 2002; Lévy, 1999; Guimarães Jr, 2000; Lemos, 2000, 2001, 2004).

Com as tecnologias digitais, portanto, o lugar ganhou um novo sentido, que extrapola sua dimensão geográfica, oportunizando que pessoas de distintos países, culturas, línguas passam a se relacionar através da rede. Ao viabilizar a conexão com qualquer parte do mundo em tempo real, o ciberespaço refutou as distâncias impostas pela geografia e permitiu tentar controlar o tempo. Assim, configurando-se como uma rede que interconecta muitos milhões de pessoas em todo o mundo, a internet é um meio de troca simbólica transnacional e comunicação interativa que possibilita ao usuário entrar no ciberespaço e experimentar as façanhas da velocidade, simultaneidade e virtualidade, encontrar-se com outros milhões de usuários e também normas, perspectivas, visões de mundo e discursos que configuram uma cibercultura que está fragmentada em distintos segmentos (Lins Ribeiro, 1997). 
As relações cotidianas que são produzidas pela apropriação e uso do Espaço Comum Luiz Estrela, constituem o plano vivido desses atores nesse ambiente (e também fora dele), contribuindo para a constituição de sua identidade e sentimento de pertencimento a um grupo. $\mathrm{Na}$ forma como, em seu dia-a-dia, constroem (e são construídos), transformam (e são transformados) e outorgam (e encontram) sentido ao espaço público, é possível pensar a produção e apropriação dos espaços públicos pelos sujeitos como relações que acontecem na horizontalidade em seu interior, dada sua capacidade de inventividade e superação de uma racionalidade planejada e dominante que busca impor-se sobre a cidade. (Sobarzo, 2006).

Isto posto, de natureza quantitativa e qualitativa, a investigação do Espaço Comum Luiz Estrela baseia-se no georreferenciamento e na etnografia de alguns grupos investigados. Em termos qualitativos, o estudo consistiu no levantamento das diferentes práticas culturais e processos de territorialização, seus locais de manifestação na cidade de Belo Horizonte, principalmente nos limites da Avenida do Contorno ${ }^{9}$, no qual foram conferidas ações e representações artísticas e culturais de diferentes segmentos sociais, como expressões musicais, literárias e grafismos.

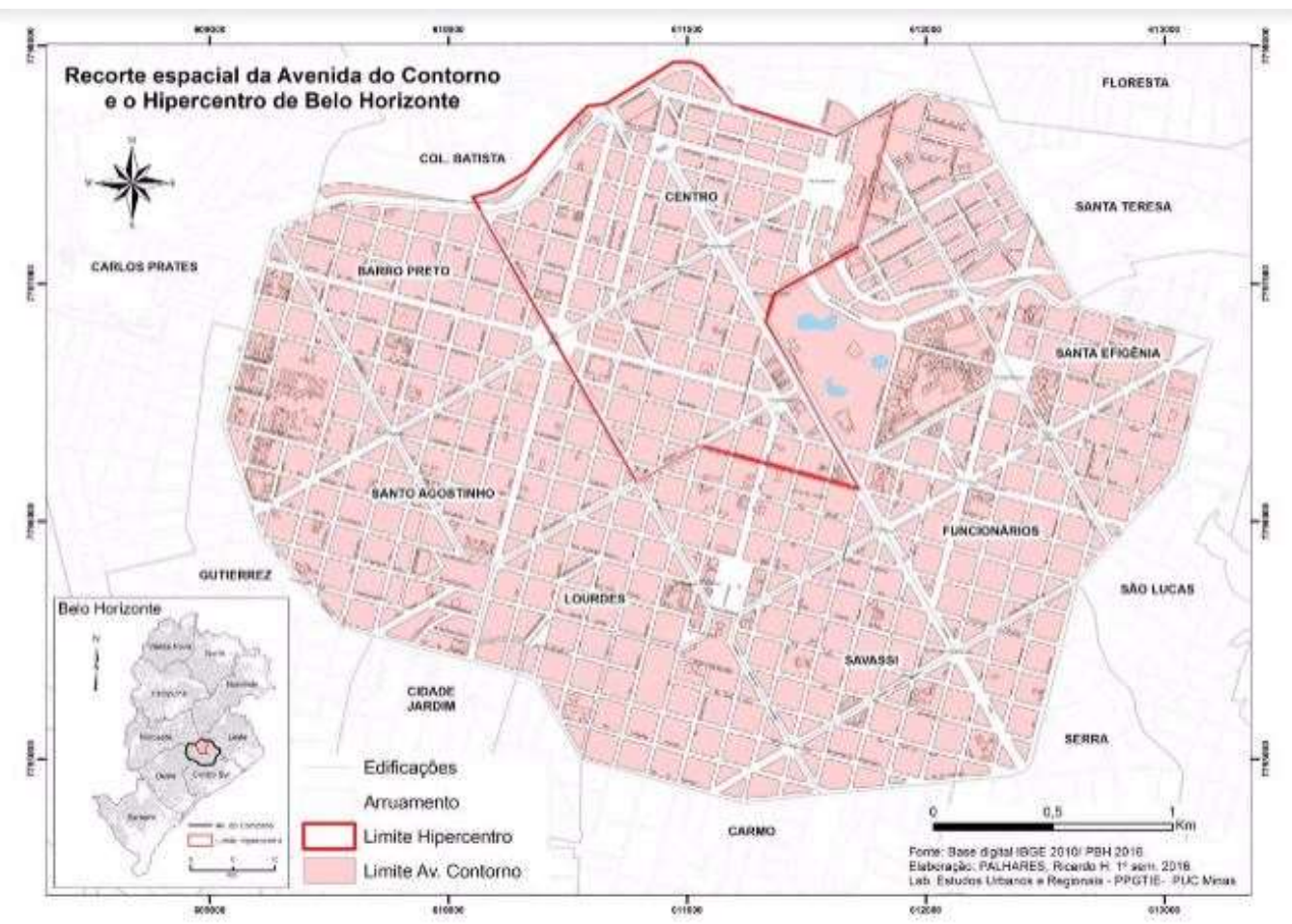

\footnotetext{
${ }^{9}$ Avenida que contorna a região central de Belo Horizonte e cujo desenho segue o traçado planejado anteriormente à construção da cidade. Originalmente, o projeto previa a urbanização apenas da área limitada pela avenida, mas com o desenvolvimento intenso no século XX a cidade ultrapassou os limites muito antes do esperado.
} 
A etnografia em espaços urbanos foi a estratégia teórica e metodológica utilizada pelos pesquisadores que investigaram os grupos no Espaço Luiz Estrela. A pesquisa de campo associou relatos e depoimentos orais, observação participante, entrevistas e registros audiovisuais.

Nesse sentido, um outro grande desafio da pesquisa foi a prática da observação participante, a coleta de depoimentos, os registros audiovisuais, o caderno de campo, como técnicas na realização de uma etnografia, ou melhor, de etnografias escritas em pequenos grupos com base na observação participante de mais de um pesquisador, como mencionado.

Por essa razão, se por um lado essa foi uma experiência muito profícua pela oportunidade de mais de um pesquisador observar a mesma atividade, por outro, o exercício da escrita demandou um esforço maior e mais criativo. Observar o mesmo fenômeno, dialogar sobre ele, expor pontos de vistas e perspectivas muitas vezes distintas, às vezes, contrastantes, exigiu um esforço incomum no tratamento dos registros etnográficos. Nesse sentido, foram enfrentados diversos desafios, e conscientes de que estávamos desenvolvendo uma experiência com etnografia de e na rua, num tempo/espaço fluidos e intensamente mutantes; e que impunha ao grupo de pesquisa compreender e compreender-se num exercício de "co-observação".

As etnografias elaboradas na pesquisa, portanto, transpuseram a experiência de um indivíduo no campo a observar e, nomeadamente, escrever na solidão do gabinete, para se concretizarem como observações, descrições e textos compartilhados. Portanto, se nos ativermos às proposições de Geertz (1978) de que a cultura é pública e de que o comportamento humano, por onde os fios destas culturas são tecidos, é ação simbólica, pois têm significados; coube aos pesquisadores alcançar mais profunda e densamente tais significados.

\section{O Espaço Comum Luiz Estrela: suas memórias e histórias}

O Espaço Comum Luiz Estrela surgiu oficialmente no dia 26 de outubro de 2013 quando um grupo de ativistas ${ }^{10}$ de Belo Horizonte ocupou um casarão histórico de

\footnotetext{
${ }^{10}$ Ativistas são os sujeitos participantes de ações políticas para construção de uma sociedade mais humana, mais justa e solidária, além da construção e concepção do Estrela. Os ativistas do Espaço Comum Luiz Estrela são oriundos de movimentos sociais, especialmente, Tarifa Zero, Ocupações Urbanas e Brigadas
} 
propriedade do governo estadual que estava abandonado há aproximadamente 19 anos, no tradicional bairro Santa Efigênia em Belo Horizonte, Minas Gerais\Brasil. É um dos maiores bairros, em extensão de área, de Belo Horizonte, dividido ao meio pela Avenida do Contorno e ao meio a Av. Brasil. E abriga a área hospitalar da capital, região onde se encontram os maiores e mais importantes hospitais públicos de Minas Gerais, além de inúmeras clínicas e consultórios médicos que ocupam prédios inteiros. É onde se localiza também a Faculdade de Medicina da Universidade Federal de Minas Gerais- UFMG. Afora tudo isso, o bairro Santa Efigênia abriga uma das áreas mais boêmias de Belo Horizonte concentrando inúmeros bares da noite, inclusive um dos mais antigos da capital que é o BAR 41 ou BRASIL 41, por estar localizado no início da Av. Brasil. Algumas casas de espetáculo encontram-se em Santa Efigênia como o Teatro Marília, Teatro da Maçonaria, Music Hall, e o Centro de Cultura Nansen Araújo (SESI- Minas). No bairro, também é localizado um dos maiores shoppings de Belo Horizonte, o Boulevard.

Neste casarão situado à rua Manaus no Santa Efigênia, funcionava anteriormente o Hospital Militar da Força Pública (atual Hospital da Polícia Militar), o primeiro deste tipo no Estado. O prédio foi construído na gestão do governador Bueno Brandão, no estilo neoclássico, com pinturas de Frederico Stechel, que havia pintado também o Hospital Central do Exército, no Rio. O ex-Governador de Minas Gerais e ex-Presidente do Brasil, Juscelino Kubitschek (1902-1976) trabalhou como cirurgião no Hospital, que também abrigou um Hospital Psiquiátrico Infantil.

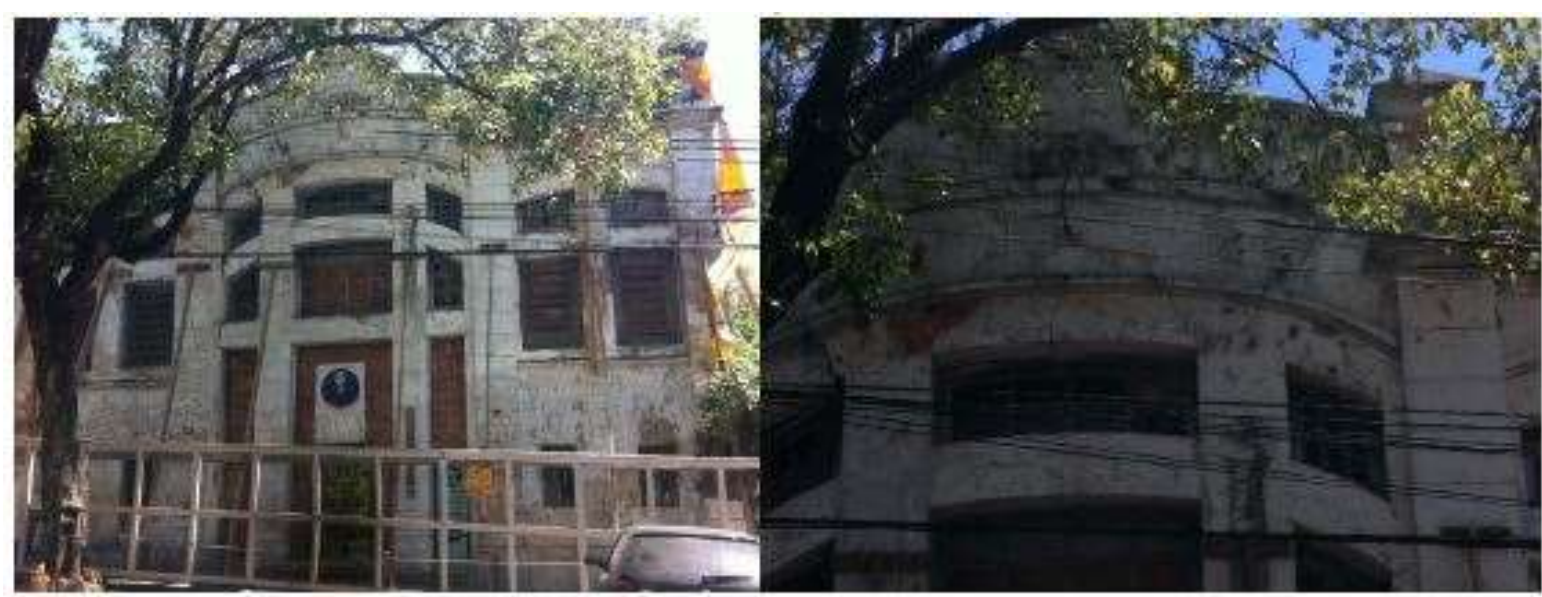

Imagens da fachada do Espaço Comum Luiz Estrela

Fonte: Arquivo Educ

Populares. São movimentos que abrangem a região metropolitana de Belo Horizonte/BH em prol da mobilidade urbana, direitos humanos e de moradia, direito à cidade e aos bens culturais e artísticos, alternativa ao mercado neoliberal do trabalho etc. 
O Casarão da Rua Manaus, 348, completou um século de existência em 2013. O local foi sede do $1^{\text {o }}$ Hospital Militar de Belo Horizonte (de 1913/1914 a 1947), do Hospital Psiquiátrico Infantil (de 1947 a 1979) e da Escola Estadual Yolanda Martins Silva voltada para alunos especiais, que funcionou no imóvel até 1994. A escolha do casarão para a ocupação se deu principalmente pelo histórico de décadas de abandono do mesmo por conta do descaso das autoridades públicas, pela localização central, o que facilitaria a participação de moradores de diferentes regiões da cidade, segundo falaram alguns de seus ativistas. E, ainda, pela possibilidade de articular a ação artístico-cultural que vinha sendo planejada junto com a área da saúde mental, visto que o imóvel faz parte da Fundação Hospitalar do Estado de Minas Gerais - FHEMIG.

A fala de Sol, um dos ativistas que participou da ocupação desde seu planejamento inicial é emblemática desta história:

O que a gente tá querendo fazer é: a gente não precisa do Estado. É uma sociedade civil organizada, intencionada, vai lá e faz. Quando a gente entrou e viu o histórico do casarão a gente sabia que ele já tinha sido hospital militar, sabia que tinha sido hospital psiquiátrico, inclusive tá lá do lado. Então a gente sabia de todos estes fatores que naturalmente influenciaram na ocupação, dentro das nossas prioridades, né? Então a gente faz reunião e um trabalho junto com o hospital para ver o que a gente consegue fazer ao máximo para ajudar estas pessoas no sistema de saúde. Pessoas sofridas! A gente também sabia que aquela casa, como em todas as casas ociosas, os moradores de rua vão, dormem, deixam as coisas. Então a gente também tinha de saber lidar. Colocar como pauta também. (Entrevista. 10/09/2014)

As histórias, memórias, lendas e relatos em torno do Hospital Psiquiátrico Infantil são inúmeras, a única certeza que se tem é que, a cada governo que passa pelo Estado e pela capital, mais detalhes desta história são perdidos. O prédio sofreu muito com o desgaste do tempo e o descaso do poder público que nada fez para preservá-lo. Em 1994, o casarão encerrou de vez as suas atividades e a arquiteta Priscila Musa, anotou num relatório parcial sobre a situação do Espaço, a existência em toda parte de trincas, fissuras, manchas de umidade, formação de pátina biológica e crescimento vegetativo na fachada.

Em entrevista concedida aos pesquisadores do Educ, Sol, uma dos integrantes do grupo de ativistas que ocupou o casarão, manifestou que todo o processo que culminou na ocupação foi exaustivamente planejado:

A gente entrou no dia 26 de outubro de 2013. Entramos lá de madrugada. Ocupamos lá todo mundo fantasiado, tocando música. Tudo já programado. Era 
só dar o start para os meios de comunicação. Foi tudo muito preparado. De abril a outubro o planejamento. Como vamos entrar? Por que vamos entrar? Como vamos relacionar com a comunidade? Como vai ser nossa justificativa jurídica? A gente teve um aparato jurídico muito forte. Tanto que o primeiro policial que viu a gente lá, viu a gente cantando: 'Nós, estamos aqui ocupando. Você pode ir embora'. E ele foi embora (risos). Ele achou que não tinha nada. Aí começou a bombar na imprensa. Ele voltou com uns amigos dele e nós dissemos: é ocupação, não, nós não vamos sair. (Entrevista. Sol, 10/09/2014).

Consultando o site ${ }^{11}$ da ocupação em agosto de 2016, o Espaço Comum Luiz Estrela surge da soma de diversas histórias que envolvem diversas experiências e desejos. "Revela memórias e convoca a responsabilidade dos cidadãos e do poder público na tarefa de devolver ao imóvel sua função social".

Como disse o ativista, a proposta de ocupação cultural surge da reunião de um grupo de artistas, ativistas, educadores, profissionais autônomos e produtores culturais que deram início a uma série de estudos e discussões sobre autogestão, cultura, cidade, políticas públicas e participação cidadã. Organizado em comissões, sempre pautado pelo cenário local e internacional, o grupo organizou a ação de ocupação cultural para criação de um centro de arte, cultura e educação autogestionado. Nesse sentido, o histórico do prédio, bem como a proximidade a uma unidade hospitalar atualmente em uso, são alguns dos eixos transversais presentes em sua proposta de ocupação/fundação.

Inspirados no filme brasileiro "Esse Amor que nos Consome", e tendo como base experiências de ocupações culturais em funcionamento no Brasil e no mundo, tais como a Ocupação Olga Vasquez ${ }^{13}$ (Buenos Aires) e o Hotel da Loucura (Rio de Janeiro) ${ }^{14}$. O Espaço Comum Luiz Estrela foi inaugurado numa manhã de primavera, com a participação direta de 80 pessoas e adesão de 2.000 pessoas por meio das redes sociais em menos de 24 horas de funcionamento, conforme constava em seu site (2016). O nome do espaço é uma homenagem ao artista de rua Luiz Estrela, morto no dia 26 de junho de

\footnotetext{
11 http://nossacausa.com/espaco-comum-luiz-estrela/

${ }^{12}$ Brasil, 2012, Cor, 80', Ficção. Filme de Allan Ribeiro, trata da especulação imobiliária através da história de um casal que vive junto há mais de 40 anos e se instalam em um casarão abandonado no centro do Rio de Janeiro. Ambos dançarinos, passam a ocupar o espaço muito mais do que com objetos, mas com o corpo. O espaço vago e abandonado passar a ser algo vivo, pulsante

${ }^{13} \mathrm{O}$ centro cultural e social Olga Vazquez parte da iniciativa de artistas, estudantes, militantes e ativistas ocuparam uma escola abandonada em Buenos Aires em 2001. O centro social e cultural propõe um modo de produção que prioriza a horizontalidade e a solidariedade, na qual todos são parte ativa do processo de produção dos bens culturais, que aposta no processo de cultura coletiva, a partir da história do país. $\mathrm{O}$ espaço possui uma dinâmica de cooperativa que emprega artistas, trabalhadores e interessados em contribuir com o centro, mantendo suas ações de maneira sustentável, com dignidade e sem exploração.

${ }^{14} \mathrm{O}$ Hotel da Loucura é uma ocupação cultural que funciona no terceiro andar do hospital psiquiátrico Instituto Nise de Silveira, no bairro do Engenho de Dentro, zona norte do Rio de Janeiro.
} 
2013 em Belo Horizonte. Estrela era poeta, performer, intelectual, morador "na" ou "de" rua, homossexual e devotado militante da causa, chegando em dado momento a integrar Gang das Bonecas ${ }^{15}$. Trazia consigo a luta do artista pela arte, a luta do cidadão pelo direito à vida e à cidade. De acordo com o site portal Aprendiz $\mathrm{Uol}^{16}$ :

Em 26 de junho de 2013, enquanto discutia-se a possível ocupação do casarão abandonado, morria, nas ruas de Belo Horizonte, o morador de rua negro, homossexual, alcoólatra, paciente da saúde mental, artesão, poeta e perfomer Luiz Otávio, ou Luiz Estrela, em circunstâncias até hoje não elucidadas, no mesmo dia em que uma manifestação contra a Copa do Mundo acontecia. Sua trajetória batizou o espaço e essa ideia de comum: um lugar onde todas as decisões sobre o espaço são tomadas em reuniões e assembleias.

Sabemos, também, que o nome do espaço é marcado por muitas lendas, relatos e principalmente mistérios. Luiz Otávio da Silva, foi brutalmente espancado no dia 26 de junho de 2013. Em razão de sua personalidade expansiva e o fato de ser um grande amigo de todos fez com que o Espaço recebesse o nome em sua homenagem. Luiz Estrela conseguia conciliar todos os elementos que dariam jus a escolha do seu nome para o Espaço, ser um morador na rua e estar sempre aberto para a vivência de todos. O Espaço Comum Luiz Estrela se propõe a ser um local onde a poesia marginal, que outrora era desconsiderada, tenha um espaço de destaque. Há ainda o seguinte relato:

O nome é homenagem a Luiz Estrela, jovem poeta e morador de rua da região. Com o grupo "Gangue das Bonecas", ele participou de diversas intervenções sobre gênero e diversidade sexual nas ruas de $\mathrm{BH}$, até que um dia, na Copa das Confederações, foi espancado até a morte, num assassinato cuja origem nunca foi investigada. Ao tom de perucas e violinos, sua figura foi a única intervenção consensuada nas paredes do Espaço em risco de queda. (Outras palavras, $\left.2016^{17}\right)$.

\footnotetext{
15 A Gangue das Bonecas é formada por atores profissionais e pessoas em situação de rua, que criam Intervenções Urbanas a partir de discussões sobre gênero e sexualidade. Composto por mulheres, homens e transgêneros; hetero e homossexuais; o grupo se reúne no Centro de Referência da População de Rua de Belo Horizonte para trocar experiências, impressões e discutir questões relacionadas à diversidade sexual. Apostando no convívio, na troca e na coletividade, o projeto desenvolve ações artísticas e reflexões sobre direitos humanos, teatro contemporâneo, tolerância, identidade sexual, inclusão e cidadania. Disponível: https://aganguedasbonecas.wordpress.com/

${ }^{16} \mathrm{http}$ ://portal.aprendiz.uol.com.br/2015/02/06/espaco-comum-luiz-estrela-autonomia-arte-e-ocupacaoem-prol-do-direito-a-cidade/ Acesso em agosto de 2016.

${ }^{17}$ http://outraspalavras.net/blog/2013/11/22/nasce-uma-estrela-em-belo-horizonte-uma-poesiapolitica/ Acesso em março de 2016.
} 
Em outro relato, o ator Jonas Vidigal, de 30 anos lembra que "Ele morreu com cabelo rosa". Essa é uma das lembranças deixadas por Luiz Otávio da Silva, o multiartista que se autodenominava estrela. Luiz Estrela. (Caderno Divirta-se, 2015)

Como todo mito de fundação, sem dúvida, este homem, Luiz Otávio, convertido e entronizado Luiz Estrela, é cercado de histórias, memórias, lendas e alegorias. Quem foi realmente Luiz Estrela cujo carisma alimenta o ideário da ocupação e é tributário da alma do projeto da mesma: ser um espaço comum, ser o comum, onde todos comungam de um mesmo sonho: mostrar à cidade que outra cidade é possível?

Com efeito, os mitos têm uma história de interpretações no Ocidente que remonta ao menos ao século XVIII. Durante muito tempo, pensou-se que os mitos expressavam a primeira forma de linguagem da humanidade, ou que seria um fenómeno característicamente religioso na medida em que sempre remete a estórias de origen com alto valor de cunho moral. Objeto de reflexões no campo da história comparada das religiões e dos fenomenólogos, os mitos merecerão de muitos estudiosos a atenção por toda uma vida: Joseph Campbell (1904-1987), Mircea Eliade (1907-1986), Georges Dumézil (1898-1986) entre outros.

No campo da antropologia, os mitos são temas de fundação dessa disciplina e receberam de antropólogos explicações e leituras memoráveis como, por exemplo, Bronislaw Malinowski (1884-1942), com sua análise do "mito na psicologia primitiva". Mas, sem dúvida, a abordagem estruturalista realizada por Claude Lévi-Strauss (19082009) a partir dos anos 1960 é que mais vai tomar mitos e ritos como valoroso objeto de investigação. Nesta mesma matriz disciplinar, a antropologia, é preciso estar atento para a polissemia conceitual dos mitos já que são portadores de sentidos diferentes quando utilizados em contextos diferentes.

\footnotetext{
Normalmente vistos como estorias fantasiosas e irreais, cujo parentesco com a mentira parece inegável, os mitos se contrapõem à história enquanto relato verdadeiro sobre o que aconteceu. Mas, a questão da verdade ou veracidade dos episódios e fatos não estão no centro da narrativa mítica. Com efeito, este conjunto de representações já prenunciam a sua principal qualidade simbólica que é a de se alimentar das contradições. Haja vista que os "mitos", via de regra, são portadores de mais de uma versão sobre episódios, acontecimentos, entidades e pessoas, bem como, são estórias carregadas de situações ambivalentes, liminares, em que as oposições, os contrários, cedem lugar ou se revelam cada vez mais vivo do que nunca. (ROCHA IN: TOSTA e ROCHA, 2011)
} 
A verdade é que tomando o acontecimento da Ocupação, como analisa DaMatta (1997) mitos são narrativas que dizem respeito a nós mesmos e sobre nós e que que contamos a nós mesmos, revelando muito da nossa estrutura de pensamento simbólico. $\mathrm{O}$ que fica evidenciado na ritualização da história da Ocupação, por ocasião de seu aniversário com a performática realização do teatro cuja representação é esta história. Em certo sentido, podem ser vistos como uma outra forma de narrar uma história- como estória, o que a distingue da produção historiográfica documental-oficial. Por isso o que mais importa não é a veracidade ou não do acontecimento, mas a sua potente eficácia simbólica que mobiliza e ritualmente se mantém fortalecido e vivo um projeto, como no caso da Ocupação.

Sem dúvida, pelas inúmeras estórias contadas sobre o Espaço Comum Luiz Estrela, “O objetivo da ocupação é dar vida a uma casa pública com atividades formativas, vivências artísticas, culturais e políticas abertas propostas por todas as pessoas interessadas em participar dessa construção colaborativa", defende Manu Pessoa, artista, atriz e ativista do Espaço Comum. (Portal Uol, 2016). É a ativista quem complementa:

\begin{abstract}
A experiência do Espaço Comum Luiz Estrela representa, no contexto de Belo Horizonte, a urgência, a possibilidade de existência e a potência de uma cultura independente, livre das amarras do mercado e dos mecanismos de incentivo. Representa, ainda, o desejo compartilhado da sociedade assumir para si as rédeas dos processos de transformação e de efetivá-los coletivamente e colaborativamente, salvaguardando, independentemente do poder público, a memória da cidade. (Portal Uol, 2016).
\end{abstract}

E o imóvel, até então praticamente desconhecido da população e largado ao acaso pelo Estado, revelou potencial para uma compreensão mais consistente e polissêmica do que seja a cidade, o urbano em termos de suas contradições, diferenças e desigualdades como espaço público:

Sua estrutura frágil e a aparência que marca o abandono do espaço público de modo geral, aos poucos foi dando vida a um emaranhado de vozes ocultas, invisibilidadas. A cada cômodo da casa em cada fissura observada, em cada parede desbotada, surgem sinais dos tempos sombrios que se apresentam como raios de luz adormecidos, "há uma rachadura em tudo, é assim que luz a entra" (Leonardo Cohen, citado em docplayer ${ }^{18}, 2016$ ).

\footnotetext{
${ }^{18} \mathrm{http}: / /$ docplayer.com.br/3285670-Esboco-de-projeto _espaco-comum-luiz-estrela-introducao.html
} 
De acordo com um dos documentos eletrônicos que narra a história do Estrela,

\begin{abstract}
Sua estrutura segregadora, carcerária e seu obscuro porão aos fundos tecem a narrativa de uma história de loucura, abandono e dor. Os relatos de vizinhos, antigos e ex-funcionários e até de ex-internos, foram alinhavando fragmentos desconexos sobre o espaço. A memória aos poucos foi se revelando e apontando as potencialidades do antigo casarão: a história de crianças internadas e em tratamento no sistema psiquiátrico da época, a aversão moderna àquilo que questiona e desafia, e incapacidade da sociedade em propor ações alternativas ao uso da violência. Diante das descobertas os planos traçados inicialmente ganharam novas configurações apontadas pelo próprio espaço. O coletivo envolvido na ocupação cultural se deparou com a seguinte responsabilidade: dar vida àquela edificação e trazer à superfície sua história oculta, dando voz àqueles que permaneceram durante longo período submersos. Além disso, se antes o espaço foi sede de tratamentos psiquiátricos desumanos, atualmente condenados, como a lobotomia e o eletrochoque, hoje o espaço recebe a arte e a cultura como prática cidadã. (docplayer, 2016).
\end{abstract}

Se o redescobrimento de espaços como o casarão ocupado implica o reencontro de sua memória num determinado lugar, a relação com os moradores da região não é tão simples. Talvez pela própria história do casarão em suas diversas atividades- hospital militar, psiquiátrico, escola de atendimento a crianças "especiais", para, finalmente, ser literalmente abandonado à sorte e descaso das políticas públicas no nível estadual e municipal, que se torna estigmatizado e, de algum modo, amaldiçoado. Contudo, o medo e resistência de parte da comunidade do entorno, deu lugar à ocupação praticada por gerações jovens e adultas, cuja objetivo maior é propiciar uma vivência coletiva e comum, provocando aquele imaginário negativo do entorno e propondo novas relações com a arte, o patrimônio, a história, a memória e suas próprias formas de habitar.

A elaboração do projeto da Ocupação, que, além de conter uma série de reflexões gestadas desde o início do processo,

contou com quatro longas rodas de conversa entre ocupantes e frequentadores do Espaço Comum e um encontro realizado com a comunidade do entorno. Aqui, parte-se do princípio de que um projeto acabado se mostra inadequado ao se tratar de uma iniciativa colaborativa, participativa e continuada e que os contornos dos planos de ocupação permanente devem ser gestados de forma gradativa, junto com o amadurecimento das relações com o espaço e com a cidade. (docplayer, 2016) 
O Esboço de Projeto - Espaço Comum Luiz Estrela, agora não mais considerado como "ocupação", como nos disse um ativista e orgânico ${ }^{19}$ : "O Luiz Estrela foi uma ocupação porque a partir de dezembro/2013 ganhou o direito de posse. Portanto, não é mais uma ocupação. O objetivo inicial foi encher a paciência do governo e forçá-lo a olhar para esses espaços abandonados”. (Entrevista. 24-10-2014). Para tanto, ele foi planejado para um período de dois anos foi organizado nos seguintes tópicos:

1-Estruturação e Autogestão: Tem como propósito consolidar um modelo de autogestão constituído por um sistema de organização autogestionário, que preserva a horizontalidade e não-hierarquização. A concepção de cogestão/autogestão está implicada no Espaço através de um conjunto social formado por grupos e indivíduos autônomos, coletivos e militantes que tem essa diretriz aplicada tanto em suas funções econômicas de produção quanto nas suas funções políticas. No sistema da autogestão, conforme destacaram os entrevistados, não há a presença de um coordenador acima de todos, mas uma organização coletiva em que todos os indivíduos têm ampla liberdade de expressão e fiscalização, tendo como eixo orientador um estatuto ou regimento interno, disposto a ser modificado de acordo com as demandas e decisões fundamentais consensuadas ao longo do processo através de espaços de diálogo, reuniões e assembleias. A proposta para a sustentabilidade financeira do Espaço será pautada nos princípios da economia solidária.

Na tentativa de uma construção de autogestão, os ativistas do Estrela se organizam em grupos temáticos e cada qual se insere naqueles que são mais próximos de suas experiências e vivências, e não há limites de grupos para cada integrante. À época da pesquisa de campo, em meados de 2014, eram aproximadamente oito entre grupos e núcleos de trabalho.

Nesses grupos, a ideia de Comum se trata de um conceito habitualmente empregado pelos ativistas e orgânicos do Estrela e está relacionado às atitudes e ações coletivas conectadas à autogestão, aos processos democráticos horizontais. Fazendo uma analogia, o comum é "tá de boa" com os princípios democráticos autogestionários. Comum no espaço urbano do casarão/espaço público abandonado pelo Estado, que foi ocupado por

\footnotetext{
19 Termos êmicos. Ativista faz referência direta aos movimentos de arte e ativismo da Literatura Marginal dos Saraus de SP e que se espalha pelo Brasil e por Belo Horizonte. Ideia muito presente no casarão. Ainda que o ativismo não se tratasse somente de natureza literária, foi nos saraus de poesia realizados nesse espaço que a expressão surgiu de modo recorrente. As pessoas orgânicas são aquelas que participam assiduamente e diretamente da construção e decisões do Espaço Comum Luiz Estrela.
} 
um conjunto de artistas (teatro, música, cinema, fotografia, etc.) e ativistas (luta pelo direito à moradia, cultura, transporte/mobilidade, educação libertária, etc)

O comum no campo das práticas dos sujeitos no território do Estrela pode ser assim definido: ele se encontraria em um estado de inacabamento, e esse estado é que movimenta todas as interações. O comum é algo para se fazer sempre em vias de ser algo. Ao mesmo tempo idealizado e ao mesmo tempo uma prática que se constitui em seu inacabamento, o comum talvez seja como uma espécie de virtual (LEVY, 1996) sempre atualizado, sempre inesgotável, pois ainda que seja posto em prática tal como pensado pelos nativos do Estrela novos desdobramentos ele indicará. Assim, novas atualizações se renovarão o que daria ao comum seu caráter de virtualidade.

O comum indica algo a ser continuamente perseguido, algo sempre em vias de. Corre-se o risco aqui de desenhá-lo com os contornos de um mito ou uma lenda, e de fato precisamos afastar tais imagens para não dar uma visão equivocada daquilo que foi pesquisado nas interações com os nativos. O comum se pauta por lutas históricas e por todo um contexto de transformações sociais que remontam as conquistas das classes trabalhadoras desde meados do século XIX. Não cabe aqui expor todas essas lutas, mas apenas deixar em relevo que, ao contrário de lendas e mitos, o comum que os nativos do Luiz Estrela compartilham encontra respaldo na história dos movimentos anarquistas. Em seus próprios moldes e reelaborações daqueles movimentos, o comum estelar pode ser interpretado com aquele caráter de virtual-atual, uma vez que é nessa dinâmica que os movimentos dos corpos se consolidam.

2-Arte, Cultura e Educação: O Espaço Comum Luiz Estrela pretende consolidar o que já vem sendo desenvolvido de forma embrionária, um lugar aberto para atividades artísticas, debates e formações, tendo como diretriz a vivência e a difusão da arte, a democratização do acesso às informações e bens culturais e a sistematização e geração de conhecimento. A casa será reformada com o intuito de ter espaços multiusos e versáteis que contemplem ações das diversas artes: música, artes cênicas, artes visuais e audiovisual. O Luiz Estrela vem funcionando como um laboratório de experimentação de trocas artísticas, culturais e educativas e o projeto permanente de ocupação cultural do casarão será construído coletivamente a partir da sistematização das práticas nele realizadas.

As ações realizadas no Espaço Comum Luiz Estrela são fruto da pesquisa e da experimentação de artistas, educadores, pesquisadores e ativistas de diversas áreas do conhecimento popular. As vivências coletivas são respostas a desejos e anseios por novas 
formas de abordagem da arte, da cultura e da educação. A arte praticada no Espaço Comum é a arte presente nas ruas, espaços públicos e equipamentos culturais da cidade reconfigurada sob a ótica do encontro, da colaboração e da horizontalidade. No Espaço Comum, artista e público ocupam a rua, sob o mesmo ponto de vista, com olhares que miram um horizonte comum.

Da mesma forma a educação é pensada entre os ativistas e frequentadores do Espaço como espaço de troca de saberes e experiências, onde é possível ensinar e aprender, construir novos sentidos e valores no coletivo. Nesse sentido, cabe resgatar as ideias do filósofo colombiano Bernardo Toro (2004), que afirma que a educação sozinha não tem forças para fazer grandes mudanças, mas que nenhuma grande mudança se faz sem a educação. Educar é criar condições para que o potencial das pessoas, espaços e coletivos se transformem em realidade; é criar possibilidades, ampliar espaços, abrir caminhos, tornar comum.

São indicadas algumas das possibilidades de atividades culturais, artísticas e educativas. Grande parte delas já implementadas, como: aulões e rodas de conversa abertas ao público ofertadas por professores, especialistas, estudantes e pesquisadores de diversas áreas; oficinas com temas abertos e práticas diversas, estimulando a produção independente e a troca de experiências entre os participantes; exibições cinematográficas, prestigiando diretores, artistas e produtores independentes, partindo de temáticas grande relevância e interconexão social; exposições visuais nas mais diversas matrizes (pintura, gravura, cartaz, vídeo, grafite, entre outras), possibilitando a apresentação e o conhecimento de diferentes manifestações artísticas e culturais; espetáculos e apresentações de artistas e grupos culturais da área da música, literatura e artes cênicas, valorizando as manifestações artísticas populares (performance, canto, dança, teatro, sarau).

Nesse cometimento, os ativistas e frequentadores do Espaço consideram que para garantir a elaboração de uma cultura política participativa, universal, acessível e libertária é necessário criar formas alternativas de produção e divulgação, descentralizando e democratizando o acesso às formas existentes. Nesse sentido, cabe destacar que a ocupação cultural é o princípio motivador da criação do Espaço Comum Luiz Estrela, tendo a Cultura como eixo transversal de atuação, único capaz de abranger toda a diversidade da vivência humana e dialogar com as diversas ações já citadas acima. A arte e a cultura funcionam na dinâmica do Espaço como catalisadoras dos questionamentos e das ações políticas. Desse modo, a inauguração do Espaço Comum satisfaz um anseio 
generalizado dos cidadãos belorizontinos por um espaço não-institucionalizado, onde agentes comuns da cultura, isto é, a própria população, possa desenvolver seus projetos de forma colaborativa e participativa, independentemente da política cultural oficialmente implementada no município, reconhecida por muitos como excludente e concentradora. Portanto, a programação cultural abrigada pelo Espaço será planejada de forma democrática, universal e acessível, a partir de ofertas e demandas da população em geral.

3 - Patrimônio Cultural e Memória: O Estrela é parte do patrimônio histórico e os imóveis públicos abandonados: Por se tratar de um imóvel cuja história data desde o primeiro vintênio, após a fundação da cidade, as técnicas construtivas empregadas, tipologia da edificação, bem como o histórico de utilização trazem informações importantes não só sobre a história da própria cidade, bem como tem informações fundamentais para o delineamento histórico da saúde mental como um todo, a partir de análises arqueológicas. $\mathrm{O}$ fato de a manutenção do edifício ter sido negligenciada por décadas pelo poder público reforça a necessidade da sociedade organizada tomar a frente do processo evitando avanço do deteriora mento do bem público bem como do esquecimento da história ligada a esse patrimônio.

4 - A saúde mental: A proximidade, tanto física quanto histórica do espaço ao CEPAI, provoca uma reflexão que aprofunda o debate referente à saúde mental. Trata-se de uma concepção dinâmica de saúde, em que outras áreas e saberes devem operar conjuntamente para que os resultados sejam efetivos. É nesta perspectiva que se busca o sentido da arte como aliada neste campo. Inspirado em iniciativas como o Hotel da Loucura e afinado à luta antimanicomial, o Espaço Comum Luiz Estrela pretende se apresentar como um local de circulação, sociabilização e que reconhece a experiência artística como meio de expressão e ação criativa no cotidiano de sujeitos portadores de sofrimento mental, usuários de serviços de atenção à saúde mental da cidade.

Ademais, essa perspectiva de trabalho onde a arte e a cultura são instrumentos de sociabilidade para usuários do serviço de saúde mental está alinhada às finalidades estatutárias da FHEMIG que, em 2007, elaborou o projeto NACEIS (Núcleo de Ação Cultural, Educacional e de Inclusão Social) que também previa a destinação do imóvel para fins culturais aliado à saúde mental.

A tudo isso soma-se a situação da população de rua, que é historicamente penalizada pela falta de uso dos imóveis públicos da cidade, ao grande número de imóveis abandonados e à falta de moradia de parte de uma população. Não por acaso, o Espaço homenageia alguém que vivia nas ruas. 


\section{Algumas considerações:}

A investigação do qual se origina este texto trata-se de uma pesquisa pluridisciplinar em que articulam campos de conhecimento que, se tratam do mesmo “objeto" de investigação, neste caso, as culturas na cidade, arte e educação, cada um o faz à sua maneira e especificidade.

Reconhecendo estas especificidades é que nos colocamos frente ao desafio de pesquisar culturas, a partir de ângulos diferentes, mas que, são permeáveis e comunicantes. Em outros termos, a dimensão espacial das culturas tornou-se fundamental para compreende-las em suas intervenções e apropriações do espaço urbano. Entender a natureza dessas manifestações em termos dos sujeitos que as realizam, como realizam e como se pensam nesta realização é o aspecto central ou fundante da investigação, por isso a perspectiva antropológica com a qual os grupos e os sujeitos foram abordados e etnografados, por meio, principalmente da observação participante, mas não só. Considerar que cultura e arte são territórios que se amalgamam em torno, especialmente, das tecnologias e uso na sociedade contemporânea, exigiu que o campo das belas artes se fizesse presente.

Esta articulação porosa entre matrizes disciplinares distintas, mas declaradamente com pontos de intersecção, mostrou-se fecunda para alcançarmos os grupos de cultura em sua abrangência e múltiplas dimensões. Permitindo, assim, que os objetivos traçados para a investigação fossem alcançados. Comecemos pela retomada destes objetivos para um breve comentário conclusivo, na medida em que, as narrativas construídas polissemicamente e que compõem o enredo da pesquisa, são, ao mesmo tempo, descritivas e interpretativas. Pelo menos este foi nosso norte.

E conforme nos foi possível depreender, a categoria "juventudes” não é a mais legítima quando estes grupos de culturas são investigados, mesmo com toda a fluidez que esta noção carrega hoje. O que foi notado na composição dos grupos de culturas foi o encontro intergeracional, onde sujeitos de várias faixas etárias se colocam em diálogo e se caracterizam por certo nomandismo.

A estas altura nos resta perguntar: em que medida a ocupação de um espaço com uma história cravada e vivificada na memória de seus usos e finalidades, nos revela o quê, para a compreensão do presente? Em outros termos, como o passado é evocado constantemente nos discursos dos ocupantes do casarão da Rua Manaus e na própria 
narrativa midiática que cobre o acontecimento, numa espécie de celebração de recusa e de restauração daquele espaço?

Desde estes questionamentos, mas sem a pretensão de dar expostas totalizantes, a ocupação Luiz Estrela, num movimento político de resgate do casarão pretende ser um espaço de acolhida bastante plural e inclusivo, apontando possibilidades de interpelar a vida social como se apresenta e experimentar alternativas. Além de servir de lugar para o encontro de grupos, a formação em artes, encenação de múltiplas linguagens e encontros para a discussão e reflexão em torno de projetos de vida, tem sido, também, um espaço informal de convivência de moradores em situação de rua na rede de proteção e assistência social voltada a esse segmento da população. Várias pessoas nesta situação participavam das atividades culturais, oficinas e banquetes públicos oferecidos pelo Espaço Comum Luiz Estrela.

Outro aspecto importante é que a história do Espaço Comum Luiz Estrela e dos demais grupos investigados conta sobre uma articulação com movimentos sociais no Brasil e no exterior, cujo objetivo central é o debate e as ações permanentes de coletivos que, de muitos modos, querem ser visibilizados e ouvidos em seus modos de ser e de participar da cidade. Modos esses de atuar e intervir que nem sempre coadunam com políticas públicas que dizem respeito à educação, à apropriação da cidade, às culturas e, finalmente, a uma ordem social estabelecida. Diante disto, tais grupos mostram toda sua riqueza, versatilidade no manejo das tecnologias e do fazer arte e seu potente discurso crítico à sociedade contemporânea, apontando alternativas políticas, culturais e econômicas ao modus operandi do status quo hegemônico.

Ademais, embora os integrantes do Estrela tivessem posicionamentos diferentes, tinham os mesmos objetivos: construção de uma sociedade mais humana e solidária. A construção da autogestão é a materialização desses objetivos. Por isso mesmo, é cheio de polêmicas, contradições, disputas de ideias etc. Embora autogestão pressuponha um movimento anti-hierárquico, há no Espaço pessoas que assumem de fato a construção do Espaço Comum Luiz Estrela. O que foi possível perceber também que essas pessoas são fundamentais para sustentar e segurar o movimento. Isso não quer dizer que sejam líderes ou coordenadores, no seu entendimento, mas são destacadamente referências nesse processo.

Enfim, é possível uma organização comunitária diversa, em que pessoas discutem e chegam a um consenso em favor do bem comum, por um movimento de pensamento 
crítico e de análise conjuntural, sem abrir mão de seus princípios, mas coordenando ações comunitárias.

Ao conjunto de objetivos elencados neste texto e que guardam princípios de ordem histórica, política, cultural, econômica, ética e social, são apontadas ações prioritárias e estratégicas para a consecução dos mesmos. Ações sempre em regime de horizontalidade, autogestionário, colaborativo e envolvente, que revelam um modo ou múltiplos modos de fazer política compreendida como uma ação que permeia e é intrínseca ao cotidiano dos grupos e dos sujeitos presentes na Ocupação Luiz Estrela e arredores.

São redes de sociabilidade que se tecem e entretecem com maior ou menor duração, abertas aos imponderáveis que cercam sua realidade, que como nós, feitos ou desfeitos para serem refeitos, vão formando uma tessitura que transborda arte, criatividade e posturas profundamente críticas à ordem social hegemônica, anunciando material e simbolicamente que uma outra sociedade é possível.

\section{Referências Bibliográficas:}

ABROMAVAY, Miriam et al.. Gangues, galeras, chegados e rappers: juventude, violência e cidadania nas cidades da periferia de Brasília. Rio de Janeiro: Garamond, 1999.

BAUMAN, Zygmunt. Modernidade líquida. Rio de Janeiro: Jorge Zahar, 2005.

CARRANO, Paulo C. Rodrigues. Identidades juvenis e escola. Alfabetização e Cidadania, São Paulo: Rede de Apoio à Ação Alfabetizadora no Brasil (RAAAB), n.10, p.16, nov. 2000.

DaMatta, Roberto. A casa e a Rua: espaço, cidadania, mulher e a morte no Brasil. 5 ed.Rio de Janeiro: Rocco, 1997.

DAYRELL, Juarez. A música entra em cena: o rap e o funk na socialização da juventude. Belo Horizonte: Ed. da UFMG, 2005,

. A escola faz as juventudes?: reflexões em torno da socialização juvenil. Educ. Soc., Campinas, v. 28, n. 100. (Especial), p. 1105-1128, out. 2007.

ECKERT, Cornelia; ROCHA, Ana Luiza Carvalho da. Antropologia da e na cidade, interpretações sobre as formas da vida urbana. Porto Alegre: Marcavisual, 2013.

EVANS, L. Grupo ocupa casarão no Santa Efigênia para transformá-lo em espaço cultural. Disponível: $<$ http://www.em.com.br/app/noticia/gerais/2013/10/26/interna_gerais,4641 
16/grupo-ocupa-casarao-no-santa-efigencia-para-transforma-lo-em-espacocultural.shtml> Acessado em: 25 setembro 2014.)

Disponível em: $<$ http://docplayer.com.br/3285670-Esboco-de-projeto_-espaco-comumluiz-estrela-introducao.html $>$. Consulta em 10\12\2015

Disponível em: <http://outraspalavras.net/blog/2013/11/22/nasce-uma-estrela-em-belohorizonte-uma-poesia-politica/> Acessado em 19\02\2016

Disponível em: $<$ http://divirtase.uai.com.br/app/noticia/musica/2014/11/06/noticia_musica,161142/espaco-comumluiz-estrela-completa-um-ano-em-bh.shtml>. Acessado em 27\02\2016

Disponível em: https://aganguedasbonecas.wordpress.com/ Acessado em 27\02\2016)

GEERTZ, Clifford. Obras e vidas: o antropólogo como autor. Rio de Janeiro: Editora UFRJ, 2002.

HOLSTON, J. Espaços de cidadania insurgente. In. Revista do Patrimônio Histórico e Artístico Nacional, n. 24, 1996.

LEFEBVRE, Henri. El derecho a la ciudad. Barcelona: Peninsula, 1978.

MAGNANI, José Guilherme Cantor. Introdução - circuito de jovens. In: MAGNANI, José Guilherme Cantor; SOUZA, Bruna Mantese. (Org.). Jovens na metrópole: etnografias de circuitos de lazer, encontro e sociabilidade. São Paulo: Editora Terceiro Nome. 2007.

ROCHA, Gilmar.. TOSTA, S. P. 2013. Antropologia \& Educação (2. Ed.). Belo Horizonte: Autêntica Editora.

ROCHA, G. Mito. In: TOSTA, S. P. ROCHA, G. (org.). 2011. Enciclopédia INTERCOMAntropologia da Comunicação. São Paulo: Intercom. CD.

ROCHA, A. Grupo cultural ocupa casarão abandonado da Fhemig no Santa Efigênia. (Disponível em: <http://www.otempo.com.br/cidades/grupo-cultural-ocupacasar\%C3\%A3o-abandonado-da-fhemig-no-santa-efig\%C3\%AAnia-1.737322> Acessado em: 25 setembro 2014.)

LINS RIBEIRO, Gustavo. 1996. Internet e a comunidade transnacional imaginada-virtual.

Série Antropologia. (198). Brasília. Disponível em:

http://vsites.unb.br/ics/dan/Serie198empdf.pdf Acesso em 02.05.11

LINS RIBEIRO, G.1997. A condição da transnacionalidade. Série Antropologia, Brasília, v. 223, p.1-34, 1997

LINS RIBEIRO, G. 2002. El espacio público virtual. Série Antropologia. (318). Brasília. Disponível em: http://vsites.unb.br/ics/dan/Serie318empdf.pdf Acesso em 23.04.11

LINS RIBEIRO, G. 2006. Síntese da mesa redonda Cultura, identidade e política na Era da informação. Rio de Janeiro. Trabalho apresentado no Seminário internacional Desenvolvimento em Questão: que sociedade da informação e do conhecimento? Organizado pelo Laboratório Interdisciplinar sobre a Informação e o Conhecimento - Liinc (UFRJ - Ibict). 
MAFFESOLI, M. 2001. Sobre o nomadismo: vagabundagens pós-modernas. Rio de Janeiro: Record.

MAGNANI, José Guilherme Cantor. Transformações na cultura urbana das grandes metrópoles. São Paulo: UFSCAR, 2014. Disponível em: < http://migre.me/smstM $>$. Acesso em: $10 / 12 / 2015$

MARGULIS, Mario \& URRESTI, Marcelo. "La juventud es más que una palabra". In: Margulis, M. (org.). La juventud es más que una palabra. Buenos Aires, Biblos, 1996.

PERALVA, Angelina. O jovem como modelo cultural. In: Juventude e contemporaneidade. São Paulo: Revista Brasileira de Educação, ANPED, 1997, números 5 e 6.

SIMMEL, Georg._Questões fundamentais da sociologia. Rio de Janeiro: Zahar, 2006.

SOBARZO, Oscar. A Produção do Espaço Público: da dominação à apropriação. In: GEOUSP, Espaço e Tempo 19. Revista de Pós-Graduação/ Departamento de Geografia, Faculdade de Filosofia, Letras e Ciências Humanas. Universidade de São Paulo - nº 19 (2006) - São Paulo: FFLCH/USP, 2006

TORO, José Bernardo. WERNECK, Nísia Maria Duarte. Mobilização social- Um modo de construir a democracia e a participação. Belo Horizonte: Autêntica, 2004. Disponível em: $<$ http://portal.aprendiz.uol.com.br/2015/02/06/espaco-comum-luiz-estrela-autonomia-artee-ocupacao-em-prol-do-direito-a-cidade/>. Consulta em $19 \backslash 02 \backslash 2016$

TOSTA, S. P. Sociabilidades Contemporâneas: jovens em escolas. In: Ana Maria Casasanta Peixoto; Mauro Passos. (Org.). A escola e seus atores- educação e profissão docente. 1 ed. Belo Horizonte: Autêntica, 2005, v. 183, p. 197-220.

TOSTA, S. P. et.al. CULTURAS URBANAS: Georreferenciamento e Análise Cultural de Grupos Juvenis em sua relação com a Escola, as tecnologias e com a cidade de Belo Horizonte/MG-Brasil. Relatório de Pesquisa. Belo Horizonte: PUC- Minas; CNPq., 2016.

SILVA, Hélio R. S.. A situação etnográfica: andar e ver. In: Horizontes Antropológicos, Porto Alegre, ano 15, n. 32, p. 171-188, jul./dez. 2009

SPÓSITO, Marília Pontes. O povo vai à escola: a luta popular pela expansão do ensino público em São Paulo. 4. ed. São Paulo: Loyola, 2002.

SPÓSITO, Marília Pontes (org.). Espaços públicos e tempos juvenis. Um estudo de ações do poder público em cidades de regiões metropolitanas brasileiras. São Paulo: Global, 2007.

ZALUAR, Alba. Gangues, galeras e quadrilhas: globalização, juventude e violência. In : VIANNA, Hermano (org.). Galeras cariocas, territórios de conflitos e encontros culturais. Rio de Janeiro: Editora da UFRJ, 1977, p. 17-58. 